ASession 2793@

\title{
Simulating Industry in the Classroom
}

\author{
By Joel Weinstein, Ron Chin, Gary Krikorian, \& Kamran Qamar \\ Northeastern University
}

\section{Introduction}

One way that engineering technology differentiates itself from other technical disciplines is in its industrial flavor. Engineering technology tries to create industry-ready technologists. From an academic perspective, most curricula do an admirable job of preparing students for the technical challenges they will face. However, academia traditionally falls very short in preparing the student for the kinds of social and political experiences that will be encountered in the real industrial world.

In the classroom, engineering students learn about circuit analysis, mechanics and programming in preparation for their jobs. However, engineering students enter the field with limited abilities to deal with the corporate literacy requirements that allow them to deal effectively with real industry-related problems such as teamwork and customer relations. Corporate literacy is a growing educational priority both nationally and locally. College students express great interest in acquiring this knowledge to supplements skills in computer technology. Once they begin to understand how companies really work, they develop great enthusiasm and confidence for hands-on technological applications, which can be combined with corporate literacy to achieve professional success. Integrating corporate literacy into the engineering curriculum has become increasingly important. Classrooms, now centers of technical learning, need to educate and teach fundamentals of corporate culture and its importance.

Simulating industry in the classroom is an excellent means of learning corporate culture. This paper describes a model for bringing together the educational, technological and corporate communities to support students in their quest to learn how to deal with the real problems of industry. It uses the implementation of software engineering and computer engineering technology as the foundation on which good corporate literacy skills can be learned. Our experience has provided substantial evidence that this type of collaboration yields important benefits for all participants, including students and the corporate world that they will eventually populate.

This paper details a single project—one of many—in which students had to complete a software solution for an imaginary client. This particular project required the design of a software solution for a small airline. The software was needed to help the airline maintain passenger reservations. 
Students dealt with the "customer" by having weekly meetings with instructors who posed as employees from the airline. At those meetings, the students developed solutions to technical problems and learned about corporate culture at the same time. At the end of the course, students submitted a working prototype and a presentation to the college faculty who posed as the corporate client. The results were enlightening and educational at the same time.

Industrial Needs

Industry demands students who understand how to think critically. The ability to think critically is a necessary skill that allows students to provide creative solutions to ill-structured problems and make effective evaluations about their solutions. In the course described in this paper, students were given problems that lacked definition, scope and detail. Unlike "cookbook" projects from previous courses which were well-defined and had clear objectives, projects in this course forced the students to establish their own goals and models and this need required critical thinking capabilities.

Critical thinking is important in industry as well as the classroom because it:

-Opens different approaches and perspectives

-Emphasizes the ability to solve problems creatively

-Is able to draw logical conclusions from collected data

-Is able to weigh competing and conflicting arguments against one another

Critical thinking is the intellectually disciplined process of actively and skillfully conceptualizing and analyzing a problem based on limited information gathered from observation, experience or communication. In the simulated industrial environment, it required the ability to separate fact from conjecture to arrive at accurate conclusions that would provide a relevant solution to a problem that lacked clarity or definition. In the simulated industrial setting posed by this class, the instructor, acting as a company representative, (deliberately) failed to provide vision, direction or timely decisions thus forcing the students to apply critical thinking to the formulation of an adequate meaningful solution.

Critical thinking can be seen as taking a set of gathered-albeit limited-information and processing the information to arrive at meaningful definitions of a problem. Because the students were given only a cursory view of the actual problem to be solved, the quality and depth of the proposed solution had to be guided by careful analysis of the problem at hand.

By forcing student teams to thoroughly define a problem, the student teams were able to articulate definitions and issues and this logically led to the need to structure a solution. The student teams were told only that they needed to create a company structure that could adequately solve the given problem. The nature of each different project forced each team to create an entity resembling a company that could deal effectively with the unique problems of each project. For example, nearly every team found the need to create an executive marketing position to interface with the customer. The guidelines for creating companies were deliberately vague so that the students had to react using their own instincts rather than following a template.

Teams were chosen in a pseudo-random fashion. It would have been natural for students to team with their friends, but this does not adequately represent what actually happens in an industrial setting. Therefore, the instructor went out of his way to create teams of individuals who did not 
previously know or regularly interact with one another. This created a serious problem that could only be solved with communication.

\section{Communication Skills}

The ability to communicate with one another is a particularly difficult one for the current generation of students. Often nicknamed the "Walkman generation," students today seem to be plugged in and tuned out. In an industrial setting, this is a recipe for disaster. Industrially, disparate departments must communicate with one another. Engineers must communicate with accountants and production personnel must communicate with marketing specialists independent of whether or not they like or understand one another.

Creating effective communications channels between team members was difficult and in many cases was impeded by the multi-cultural composition of the class. Nonetheless, this difficulty represents the current state of industry and it was important that students learn how to overcome the obstacle. The instructor was called upon many times by team members to intervene in interpersonal communications issues and squabbles and in every single case refused to get involved. The students were simply told that they had to work out their own communications problems. Once they understood that it was not possible to evict or "fire" a team member, each team sat down and ironed out their own communications problems. The techniques to solve communications issues used by each team ranged from establishing corporate dictatorships to highly democratic processes. However, although they were interesting they will not be further discussed here.

What the students learned from this exercise is that most people are victims of their own limited perceptions. Individual students are unable to find fault in their own analysis and consequently believe that their thinking and conclusions are the only accurate ones. Only when they learn how to communicate can they proceed with the last important part of the industry simulation: teamwork.

Teamwork is Essential

A student can learn technology in a classroom, but the ability to work with a team is an important real world skill that must be developed on an individual basis. Not many students have the luxury of actually interacting with real life situations within industry. Northeastern University's cooperative education program provides students with a limited timeframe in which to develop teamwork capabilities and learn how to deal with other people. In industry, poor teamwork skills or lack of skills result in team failure.

Teamwork skills require the ability and confidence to deal with any situation. Perhaps the best example of how teamwork was built comes from the student team's own log:

"What we found out was that the small details that were important to each individual play a major factor in building a successful team and how well they work with one another. One of the first things we did was to create positions and business cards for each member of the team. This gave us individual identity inside the team structure yet also showed our client and the rest of the team that we are professionals at what we do. The business card displayed our names and titles that we held within the company. This helped us and the 
client to understand who we were and who would be responsible for specific problems that needed attention.

We also created a Web page to show company production, location and personal. It was a simple page but showed the basic information that clients are interested in. There was nothing fancy because corporate America is more plain than it is animated. The site was created to let our customers know what the company was currently working on and what projects have been previously worked upon.

The group worked together to create specification and requirements sheets every week to hand in to the client. These included the meetings and topics that were discussed. Later into the project, we started to hand in more formal documents such as the Requirement Specification. They included the description of the product that was being generated to solve the clients' issue and we worked together to be sure that everyone agreed about its content. Another document included the cost and maintenance agreements. We also created manuals on the product's functionality and handed that in as well. Then at the end we worked together to prepare a portfolio which included the final documents, cover sheets, business cards and working version of the program to hand out to every representative that showed up on the day of the presentation. Working together and getting everyone to agree on a position was the hardest part of this class."

The point to be made here is that the team had real work to do and instead of completing an outline or filling in the blanks on a business plan template. They had to draw on individual abilities in real time and then had to combine them using teamwork to create a working environment, working documents and deliverables.

Student coop experiences lent an important level of experience in shaping the development of team skills that were needed to complete the project. The skills acquired from coop clearly helped the team members deal with people and environments necessary to build teams and no textbook could substitute for this is real world experience.

To further demonstrate the point about coop experiences, each student provided the following information:

\section{Gary's Co-op Experience}

My first co-op job was at leading company that provides Electronic Programmable Guides (EPGs) to the consumer electronics market. They have a research and development team focused on applying EPGs that get embedded in TVs and VCRs.

I worked in this company for one year through several coop periods as a lab technician and tester. My job was to test different firmware versions on different hardware platforms. It was a routine process testing every change on available products available to insure that they were bugfree.

In addition to testing, workers in my team had to install new versions of firmware and hardware manually in TVs and test boards for quality. The whole purpose of the process was to simulate a real- life customer environment to make sure that all the required specifications were met and that there were no problems or conflicts with other features that their products had. 
The entire working process was structured on a team basis, where we had electronic means such as email and problem report database programs to communicate with other team members as well as other employees of the company's hierarchical structure including the hardware and software developers. We also had weekly staff meetings with our team, the engineers and the chief supervisor of quality assurance.

Our team practiced critical thinking about requested results or output and every individual had responsibilities and decision-making privileges. Time was very important in software development and for that reason, the team members were given these privileges along with the responsibility of insuring that they were effective.

\section{Kamran's Co-op Experience}

Confidence was my very first lesson because my first assignment was to deal with a vice president's laptop. This was a very difficult task. When I first walked in, I could remember that I was nervous and unable to concentrate on the problem. This haunted me for the first couple of encounters, but soon I got used to it and learned new techniques about approaching authority figures in a positive manner to get the job done. It took a while for me to realize that titles do not make people superior in any way.

The next skill I acquired while on coop was communications. This did not come easily for me because interacting with people was a weakness. I was shy about approaching people and afraid of what their responses to me would be. I learned that when you approach a person, have a calm attitude and try to explain issues, it is easy to communicate with them especially if you can convince them that you are trying to solve their problem. I had to learn how to communicate in simple terms exactly what approach would be taken to cure their problem and this helped my communications skills immensely.

Another Important skill that guided me through my co-ops was teamwork. I learned how to work with a group of people and why this was important. It's like having multiple ways to fix a problem or complete a project. Within the team, everyone needed to get their part done and a delay on one member's part would delay the whole team. For example, we decided which individual would handle each task. Each took a particular task and started gathering the information required. Then one person would take all the gathered data and create a database. The project required that everyone cooperates and delivers his part on time so that the data could be entered.

\section{Ron's Co-op Experience}

I worked in a research lab with subsurface imaging that involves optics. I helped perform data acquisition for two different imaging techniques and learned various applications for these.

My first experiences with this job were getting acquainted with the lab and the atmosphere. I had never encountered such a relaxed atmosphere and was used to getting projects that had to be done by the end of the day. I learned about what goes on in a research environment. This is different from private industry because I was surrounded by scientists. There were no accountants, marketers or managers in the lab and I did not have to deal with people who did not understand the co-op experience. This was very different from my other team members in the classroom project because there was little at a research environment to show a student what it is 
like to work with people with no technical experience. When I got back into the classroom with this course, I had to adjust to a different environment than what I had experienced in my coop experience. This gave me the experience in dealing with people who do not have a technical background.

\section{The Classroom Environment}

Class lectures are often judged by how good the professor is able to present a topic and relate to students. In this particular class, lecture material provided only classical textbook information about project management and software engineering fundamentals. The real learning took place outside the class lectures. As a result, no more will be said about the formal part of the class.

\section{Group Organizations}

For the relevant coursework, each team had to choose a project from a list. The following is a typical list:

-ATM Machine

-Public Transportation Quickest Route Finder

-Courier Service Automation System

-Small Airline Reservation System

-Fast Food Automation System

-Bookstore Inventory Control System

-Building Elevator Optimizer

Teams either selected or were assigned projects from the list. Prior knowledge of any of the topics was not considered in the selection process since this more effectively represents the actual environment that would be expected in an industrial setting. The teams were told that it would be their responsibility to do whatever research was necessary to learn enough to provide a professional appearance to the customer.

Meeting with the Client

Meetings with the client were one of the most difficult parts of the student project. Meetings were scheduled only once a week during the regular class time. There were multiple groups that had to meet with the instructor/client and individual group meetings deliberately took too long resulting in many groups not having time to meet with the instructor/client. This emulation of the real world in which clients miss meetings due to illness, other commitments, etc. was a rude awakening to the student teams because just as in the real world, a delayed or missed meeting did not translate into a delayed or missed project deadline. Teams were forced to make their own decisions about issues that should have been mutually resolved during a client meeting.

Our Project - Introduction

The company that was created by the students was called Soft Solutions Inc. It consisted of the following team members:

-Kamran Qamar- CEO

-Gary Krikorian- Chief Engineer

-Ron Chin - VP Sales \& Marketing 
Each member of the team was assigned responsibilities and duties throughout the period given to complete the project. Those responsibilities were maintained and agreed upon between the members of the team at the beginning of the project.

The Customer

GONIF Airlines was our customer and operated weekdays from 9:00am to 4:00pm. Their planes must had to be back in Boston (the airline's hub) before 4:00pm each day. The system they were using was a daily scheduling table based on a blackboard for reserving flights for passengers. No airfares or passenger seating locations needed to be dealt with for our solution.

The professor was a "representative" from the client organization who was tasked with managing the student team. The representative acted only mildly interested in the project and claimed a nearly total lack of understanding of any details or procedures and generally failed to produce the requested information, documents or answers to questions.

\section{Meetings}

The team met weekly with the client although these meetings were generally unproductive. In fact, there were several times that the "client" failed to show up for the meeting at all. When the client did meet with the team, he was cordial but generally ignorant about details promising to "get back to us" although he never did.

This forced the team to formulate project information and scheduling tasks as shown below.

Details

According to the information we had, we determined that the necessary schedule included:

-Boston to Bluebell less than $1 \mathrm{Hr}$

-Bluebell to Kana less than $1 / 2 \mathrm{Hr}$

-Bluebell to Kreegah less than $1 / 2 \mathrm{Hr}$

-Kana to Beuna less than $1 \mathrm{Hr}$

-Kreegah to Beuna less than $1 \mathrm{Hr}$

Four 12-passengers planes and four 24 passengers planes are available at GONIF and a flight is cancelled due to cost constraints when it does not carry more than 4-passengers in both directions. In addition, the airline prefers to fly the small planes more often than the big planes because of fuel economy and cost issues. For that reason, the team had to come up with a solution that satisfied customer needs and solved its problems with the most efficient and least expensive method for the process (see details in Appendix.).

One of the scheduling constraints was the selection of what size plane needed to be used according to the number of passengers holding reservations for each flight. But after flight number calculations and scheduling discussions, the team recognized that it was necessary to have the same planes used for every flight: 12 passenger planes for the frequent flights and 24 passenger planes for longer flights.

Plane repair and maintenance was also considered by our decision process noting that two of the planes would be inactive each day. We chose one 12-passenger plane and one 24-passenger 
plane for this scheduled maintenance. They would have to be taken out of the daily scheduling. This service is maintained and rotated between the planes by the customer.

Activities and Methods Used

To solve the customer's problem we had to come up with a fixed flight schedule for their daily flight pattern and destinations map (details in Appendix.)

Using Tools (Software)

After research, it was determined by the team that a computer-based system would be used to implement the scheduling program. The program would use Microsoft@ Access2000. This software requires a license that had to be purchased during the integration and installation of the complete system. This software suited the needs described by the customer.

Access also allowed the project team to implement the scheduling program at a reasonable cost. It provided graphical icons for users, allowed users to use buttons to access different tables to add, edit, delete and save data accordingly.

Equipment Used as Ingredients

Personal computers were the primary tools given to the users of the system in addition to battery back up / surge protector systems for each workstation. Another important piece of equipment was a printer shared by all the users. The software package was to be installed on each computer including the scheduling program to complete the system needed to do the required job in a more efficient way.

Presentation

For final delivery, the team submitted a working prototype and a presentation to the faculty who posed as the airline company (customer.) The prototype was introduced to the customers using PowerPoint to demonstrate the problem and its results.

\section{Conclusion}

Preparing engineering technology students for the real world is not a simple task. Technical skill preparation is something that is easily grasped. In the final analysis, each of our project teams was able to master their tasks and each provided powerful convincing demonstrations of a working prototype. As educators, we can certainly take pride in the sense of realism that we have instilled in our students.

But if we are to truly prepare our students for the real world, the areas of team management and individual motivation within the team must be addressed. It was certainly the greatest challenge that these students had to face in this experience and what they have learned will no doubt be a great help for them as they enter the industrial world. 


\section{Bibliography}

1. URL: http://www.kcmetro.cc.mo.us/longview/ctac/toc.htm; Critical Thinking Resources - Longview.

2. URL: http://www-honors.ucdavis.edu/fh/index.html; Davis Honors Challenge Faculty Handbook.

3. URL: http://www.ultibase.eu.rmit.edu.au/Articles/june97/white1.htm; The PATOP Model for Thinking.

4. URL: http://www.criticalthinking.org/university/; Critical Thinking for College/University Educators.

\section{JOEL WEINSTEIN}

Joel Weinstein is the Program Coordinator for the Computer Technology curriculum at Northeastern University's School of Engineering Technology and Lowell Institute School. He has been a member of the faculty for over twenty years and has many years of service with a wide range of industrial firms.

\section{RON CHIN}

Ronald Chin is a junior undergraduate at Northeastern University's School of Engineering Technology, majoring in Computer Technology. For his first Co-op assignment, he worked for one of the campus labs that recently was granted and awarded from the National Science Foundation Research Center. There, he worked on various imaging techniques that led to a publication in an SPIE proceeding. During his free time, Mr. Chin enjoys playing hockey, golf and tennis. Mr. Chin will be receiving his B.S. in Computer Technology in June of 2002. After graduation, he plans to attend graduate school.

\section{GARY KRIKORIAN}

Gary Krikorian is an undergraduate of Engineering Technology majoring in Electrical Technology and minoring in Computer Technology at Northeastern University at Boston. He is also a member of the Golden Key Honor Society and the Boston chapter of NCSC, as part of joining the honors program provided by the college. Mr. Krikorian is a vice president of the Armenian Students Association at NEU and is involved in several cultural and educational activities. Mr. Krikorian received a B.A degree in Electrical Machinery Engineering from the University of Aleppo at Syria in 1996 and will receive a B.S. degree in Engineering Technology from Northeastern University at Boston in 2001 .

\section{KAMRAN QAMAR}

Kamran Qamar is an undergraduate student at Northeastern University who is majoring in Computer Technology. Mr. Qamar has a very interesting background in technology and dealing with hardware and software. Kamran came to Northeastern seeking more than just book knowledge, he wanted a part of the cooperative education which was offered by this institute. With this option, Mr. Qamar seeks to be overall a better-rounded individual when graduating, and he knew that unless a person does not get his/her feet wet with in the professional field, then the real world would be another challenge. Kamran's ability to learn about his surroundings has grown rapidly with his college years. A few things that he has picked up along the way are to be selective with his words and the crowd which he involves with, and that the knowledge base of a person completely depends on their ability to learn. Kamran is looking to graduate by this summer with a Bachelors degree in Computer Engineering Technology. 


\section{APPENDIX}

\section{Project Team Organization}

We are a small software company (NU project team) based in Boston, MA.

Company members are currently attending Northeastern University's School of Engineering Technology in order to get their Bachelor's Degree in Computer Technology.

All the members of the company are involved in attending courses and lectures that deal with issues and topics in software engineering.

Company Location:

23 Parsons Street

Boston, MA 02135

(617) 254-2335
Company Members:

Kamran Qamar- CEO

Ron Chin - VP Sales \& Marketing

Gary Krikorian- Chief Engineer

\section{General Purpose of the System}

\section{Existing System Purpose}

-The system is a daily scheduling table based on a blackboard for reserving flights to passengers

-No airfares and passenger seating locations are dealt with the system

\section{Airline Operating Time and Constraints}

-GONIF Airlines operates weekdays only from 9:00am to 4:00pm

-The planes must be back and kept in Boston (the main center) before 4:00pm for the next day

\section{Available Planes and Concerns}

-Four 12-passengers planes and other four 24 passengers planes are available at GONIF -A flight is cancelled when it does not carry more than 4-passengers on both ways

-GONIF prefers to fly the small planes more often than the big planes because of fuel economy and cost issues

\section{Flight Destinations, Durations, and Map}

-Boston to Bluebell less than $1 \mathrm{Hr}$

-Bluebell to Kreegah less than $1 / 2 \mathrm{Hr}$

-Bluebell to Kana

-Kana to Beuna less than $1 / 2 \mathrm{Hr}$ less than $1 \mathrm{Hr}$

-Kreegah to Beuna less than $1 \mathrm{Hr}$

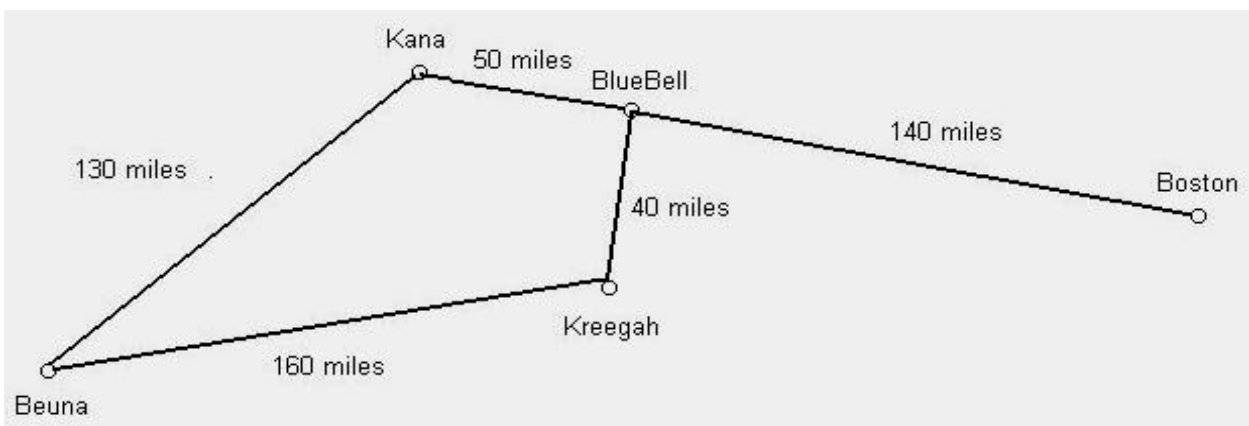

Proceedings of the 2001 American Society for Engineering Education Annual Conference \& Exposition Copyright (C) 2001, American Society for Engineering Education 


\section{Current System Information}

\section{Physical Environment}

-The existing system is located in an office

-The location is the GONIF Airline's main office

-The office environment is under normal temperature and humidity levels all the times

\section{Interfaces}

-The input is coming from the 4 users who answer the passenger's phone calls

-The output is going on the blackboard

-Used data is formatted in tabular form by writing with chalks

\section{Users and Human Factors}

-The system is used only by the reservation department employees

-The skill level of the users is high-school level

-The system is easy for the user to understand and use

\section{Functionality}

-The system presents the required passenger numbers needed for each destination and time

-The final data representation is obtained at the end of the day

-The execution speed and the system response are slow because all the users have to access the same blackboard, and they can' t be writing on the board simultaneously

\section{Data}

-The format of the input/output data is numbers and names

-All the data is received from the passengers the prior day and sent to the manager

-The data is accurate in order to make the flight scheduling decisions

-The data on the blackboard is kept until the end of that day, then it is erased to be used for the next day's scheduling

\section{Documentation}

-There is no documentation for the existing system, the users are trained by their manager

\section{Resources}

-Chalks, erasers, and phones are needed to use and maintain the operation of the system

-The system takes up the space of four desks and a BIG blackboard

-There aren't specific requirements for power, heating, and air conditioning

\section{Security}

-Only the employees of the scheduling department are allowed to use the blackboard

-All the data is shared between the four users, no isolation exists

-The system data gets backed up by one of the users on a paper at the end of the day

-The paper forms are stored daily in the manager's filing cabinet

-There are no precautions against fire, water damage, or theft

\section{Quality Assurance}

-The system is reliable and available throughout the day, but the users must maintain its data upto-date and be cautious to avoid errors

-The system cannot detect user errors at all, even for unanticipated fault 
-There is no maintenance required and the system cannot be improved further as it stands -The response time is gradual, and the amount of chalk used must be checked regularly in order to maintain the available resource

-There may be difficulty in moving the system from one location to another because of its size

\section{Problem Solving Approach}

\section{Plane Repair and Maintenance}

We've taken into account that 2 of the planes will be inactive each day; a 12-passenger plane and a 24-passenger plane. They have to be taken out of the daily scheduling because they need service for maintenance and repair. This service is maintained and rotated between the planes by the management of GONIF Airlines.

\section{Scheduling Constraints}

The airline would like a selection of what size plane they need to use according to the number of passengers they get for each flight. But after flight number calculations and scheduling discussions, our team recognized that it is necessary to have the same planes used for every flight; 12 passenger planes for the frequent flights and 24 passenger planes for longer flights.

\section{Fixed Flight Schedule}

We decided that the airline should have a fixed daily-flight schedule that addresses all the flight destinations and the flight durations with the most efficient way for the benefit of the airline.

\begin{tabular}{|c|c|c|c|}
\hline Flight \#2401 & \multicolumn{3}{|c|}{ 24 passenger plane } \\
\hline Boston To Bluebell & $9: 00 \mathrm{am}$ a1 & $11: 00 \mathrm{am} \mathbf{a} 2$ & $1: 00 \mathrm{pm} \mathbf{a 3}$ \\
\hline Bluebell To Boston & $10: 00 \mathrm{am}$ b1 & $12: 00 \mathrm{pm} \mathrm{b2}$ & $2: 00 \mathrm{pm} \mathbf{b 3}$ \\
\hline
\end{tabular}

\begin{tabular}{|c|c|c|c|c|c|}
\hline Flight \#1202 & \multicolumn{5}{|c|}{ 12 passenger plane } \\
\hline Bluebell to Kreegah & $10: 00 \mathrm{am}$ a1 & $11: 00 \mathrm{am} \mathbf{a 2}$ & $12: 00 \mathrm{pm} \mathbf{a 3}$ & $1: 00 \mathrm{pm} \mathbf{a 4}$ & $2: 00 \mathrm{pm} \mathbf{a 5}$ \\
\hline Kreegah to Bluebell & $10: 30 \mathrm{am} \mathbf{b 1}$ & $11: 30 \mathrm{am} \mathbf{b 2}$ & $12: 30 \mathrm{pm} \mathbf{b 3}$ & $1: 30 \mathrm{pm} \mathbf{b 4}$ & $2: 30 \mathrm{pm} \mathbf{b 5}$ \\
\hline
\end{tabular}

\begin{tabular}{|c|c|c|c|c|c|}
\hline Flight \#1203 & \multicolumn{5}{|c|}{ 12 passenger plane } \\
\hline Bluebell to Kana & $10: 00 \mathrm{am} \mathbf{a 1}$ & $11: 00 \mathrm{am} \mathbf{a 2}$ & $12: 00 \mathrm{pm} \mathbf{3} 3$ & $1: 00 \mathrm{pm} \mathbf{a 4}$ & $2: 00 \mathrm{pm} \mathbf{a 5}$ \\
\hline Kana To Bluebell & $10: 30 \mathrm{am} \mathbf{b 1}$ & $11: 30 \mathrm{am} \mathbf{b 2}$ & $12: 30 \mathrm{pm} \mathbf{b 3}$ & $1: 30 \mathrm{pm} \mathbf{b 4}$ & $2: 30 \mathrm{pm} \mathbf{b 5}$ \\
\hline
\end{tabular}

\begin{tabular}{|c|c|c|}
\hline Flight \#2404 & \multicolumn{2}{|c|}{ 24 passenger plane } \\
\hline Kreegah to Beuna & $10: 30 \mathrm{am}$ a1 & $12: 30 \mathrm{pm} \mathbf{a 2}$ \\
\hline Beuna to Kreegah & $11: 30 \mathrm{am}$ b1 & $1: 30 \mathrm{pmb2}$ \\
\hline
\end{tabular}

\begin{tabular}{|c|c|c|c|}
\hline Flight \#2405 \& 1206 & \multicolumn{3}{|c|}{ 24 \& 12 passenger planes } \\
\hline Kana To Beuna & \#6 10:30am a1 & $\# 5$ 11:30am a1 & \#6 12:30pma2 \\
\hline Beuna to Kana & $11: 30 \mathrm{am}$ b1 & $12: 30 \mathrm{pm} \mathrm{b1}$ & $1: 30 \mathrm{pmb2}$ \\
\hline
\end{tabular}




\section{Scheduling Example of the Proposed System}

The following is a sample of the amount of passengers called for a next day flight reservations and what the proposed system will determine for the confirmation of each flight due to the effect of the passenger amount rule.

\begin{tabular}{|c|c|c|c|}
\hline Flight \#2401 & \multicolumn{3}{|c|}{ 24 passenger plane } \\
\hline Boston To Bluebell & $\mathbf{9 : 0 0 a m}$ & $\mathbf{1 1 : 0 0 a m}$ & $\mathbf{1 : 0 0 p m}$ \\
\hline Passengers called & 14 & 2 & 4 \\
\hline Bluebell To Boston & $\mathbf{1 0 : 0 0 a m}$ & $\mathbf{1 2 : 0 0 p m}$ & $\mathbf{2 : 0 0 p m}$ \\
\hline Passengers called & 20 & 3 & 21 \\
\hline CONFIRMATION & YES & CANCELLED & YES \\
\hline
\end{tabular}

\begin{tabular}{|c|c|c|c|c|c|}
\hline Flight \#1202 & \multicolumn{5}{|c|}{ 12 passenger plane } \\
\hline Bluebell to Kreegah & $\mathbf{1 0 : 0 0 a m}$ & $11: 00 a m$ & $12: 00 p m$ & $1: 00 p m$ & $2: 00 p m$ \\
\hline Passengers called & 7 & 12 & 4 & 2 & 2 \\
\hline Kreegah to Bluebell & $10: 30 a m$ & $11: 30 a m$ & $12: 30 p m$ & $1: 30 p m$ & $2: 30 p m$ \\
\hline Passengers called & 11 & 10 & 2 & 1 & 8 \\
\hline CONFIRMATION & YES & YES & YES & CANCELLED & YES \\
\hline
\end{tabular}

\begin{tabular}{|c|c|c|c|c|c|}
\hline Flight \#1203 & \multicolumn{5}{|c|}{ 12 passenger plane } \\
\hline Bluebell to Kana & 10:00am & $11: 00 a m$ & $12: 00 p m$ & $1: 00 p m$ & $2: 00 p m$ \\
\hline Passengers called & 1 & 11 & 8 & 2 & 0 \\
\hline Kana To Bluebell & $10: 30 a m$ & $11: 30 a m$ & $12: 30 p m$ & $1: 30 p m$ & $2: 30 p m$ \\
\hline Passengers called & 3 & 6 & 4 & 8 & 6 \\
\hline CONFIRMATION & CANCELLED & YES & YES & YES & YES \\
\hline
\end{tabular}

\begin{tabular}{|c|c|c|}
\hline Flight \#2404 & \multicolumn{2}{|c|}{ 24 passenger plane } \\
\hline Kreegah to Beuna & $\mathbf{1 0 : 3 0 a m ~}$ & $\mathbf{1 2 : 3 0 p m}$ \\
\hline Passengers called & 23 & 10 \\
\hline Beuna to Kreegah & $\mathbf{1 1 : 3 0 a m}$ & $\mathbf{1 : 3 0 p m}$ \\
\hline Passengers called & 17 & 19 \\
\hline CONFIRMATION & YES & YES \\
\hline
\end{tabular}

\begin{tabular}{|c|c|c|c|}
\hline Flight \#2405 \& 1206 & \multicolumn{3}{|c|}{ 24 \& 12 passenger planes } \\
\hline Kana To Beuna & \#6 10:30am & \#5 11:30am & \#6 12:30pm \\
\hline Passengers called & 5 & 10 & 9 \\
\hline Beuna to Kana & $\mathbf{1 1 : 3 0 a m}$ & $\mathbf{1 2 : 3 0 p m}$ & $\mathbf{1 : 3 0 p m}$ \\
\hline Passengers called & 2 & 16 & 5 \\
\hline CONFIRMATION & CANCELLED & YES & YES \\
\hline
\end{tabular}




\section{Detailed Characteristics of the Proposed System}

\section{Physical Environment}

-The system will be located in the main Airline office as the previous one

-The office environment is still under the same temperature and humidity levels

\section{Interfaces}

-The input will be coming from one of the users, who takes passengers' information and request by typing it on the computer

-The output is going to be on the computer screen and user-requested paper forms

-Used data is formatted into a database using Microsoft ${ }^{\circledR}$ Access 2000

\section{Users and Human Factors}

-The system will still be used by the reservation department employees

-The skill level of the users must be developed by training for basic computer knowledge

-The system will be easy for the user to understand because it's based on simple interface

\section{Functionality}

-The system presents the required passenger information, their reservations for each flight, and if the flight will be cancelled or not according to the passenger number rule

-The data representation can be obtained anytime during the day

-The execution speed and the system response will be faster than the existing system

\section{Data}

-The type of the input/output data will be contact information, such as name, last name, address, phone numbers, availability, destination, flight IDs, etc.

-The data and the reservation request will be received from the passengers, input into the system the prior day, and the final flight confirmations will be ready at the end of that day

-The data output must be accurate in order to have the correct flight schedule

-The data will be stored as a file into the system and also backed up to a storage device, in addition to the paper reports that can be saved in a secure cabinet for reference

\section{Documentation}

There will be a simple instruction set for using the system that is not a detailed user manual, and the users must be trained by our company

\section{Resources}

-Power, computers, and phones will be needed to build and use the system

-The system will require less office space compared to the existing system

-The location must maintain the same requirements for power, heating, and air conditioning

-The system must be developed and delivered on 8/25/2000

-The amount of money to be spent to develop the system must be less than $\$ 300,000$

\section{Security}

-Only the assigned users will have access to the system by PIN numbers

-The database will be shared between the four users though their individual terminals

-The data will be saved automatically and backed up daily to a storage device

-Paper reports can also be obtained and saved in a secure cabinet

-There are no precautions against fire, water damage, or theft 


\section{Quality Assurance}

-The system is reliable and available throughout the day

-The system will be able to detect some user errors

-If a user terminal or the whole system fails, three minutes are needed to restart the system -Maintenance will be required to correct some design errors and also to improve the system

In case of a power failure, the Uninterrupted Power Supply Units (UPS) will maintain the operation of the system until the electrical problem is resolved

Moving the system from one location to another will be easier because of its size, but it has to be done by a certified technician to prevent shock hazards and damages to the system

\section{Proposed Project Techniques and Tools}

After research, our team determined that we would be using a computer-based system in order to implement our designed scheduling program. The program will be Microsoft $₫$ software, Access 2000 that will run with Microsoft ${ }^{\circledR}$ Windows98. The software involve licenses that will be purchased during the integration and installation of the complete system.

This software package suits the needs that have been described by the customer. Access will also allow the project team to implement the scheduling program at an efficient cost. Microsoft ${ }^{\circledR}$ Access 2000 will be the easiest program as it seems because it is as simple as clicking few buttons.

The duo of Windows98 and Access 2000 will make this project a complete success, as the team has decided to implement and use this tool for the final product. Both of the programs offer graphical icons for the users to understand the system easily.

Realizing from our company's experience, our project team has learned that new computer users are more at ease with systems that have a graphical touch to it, then just a black screen with text for contents. Microsoft ${ }^{\circledR}$ Access 2000 allows the user to use buttons to get into different tables, to add, edit, delete, and save data accordingly.

\section{System Operation Environment}

\section{Support}

Support will be given from Soft-Solutions as part of the maintenance agreement. Associates from Soft-Solutions can be contacted for any problems that may occur with the scheduling system.

\section{Security}

The security of this system will involve protecting the software data from other employees by means of individual passwords for each user. The user data is periodically saved on the computer that holds the shared database. The data will also be backed up by one of the users and given to the manager in order to have that data in a secure place for fire and theft precautions. 


\section{Privacy}

User-specific login names and PIN numbers are used to logon to each computer terminal in order to insure that the airline's reservation department employees are the only persons able to access the system in addition to the manager and the system administrators (or developers).

\section{Integrity}

The daily report information will also give the company a hard copy of the needed information in case the main computer that holds the shared database fails due to hardware or any software problems. In case of failure, the data can be retrieved from the backup files on the storage device and the paper reports obtained for that day.

\section{Project Schedule}

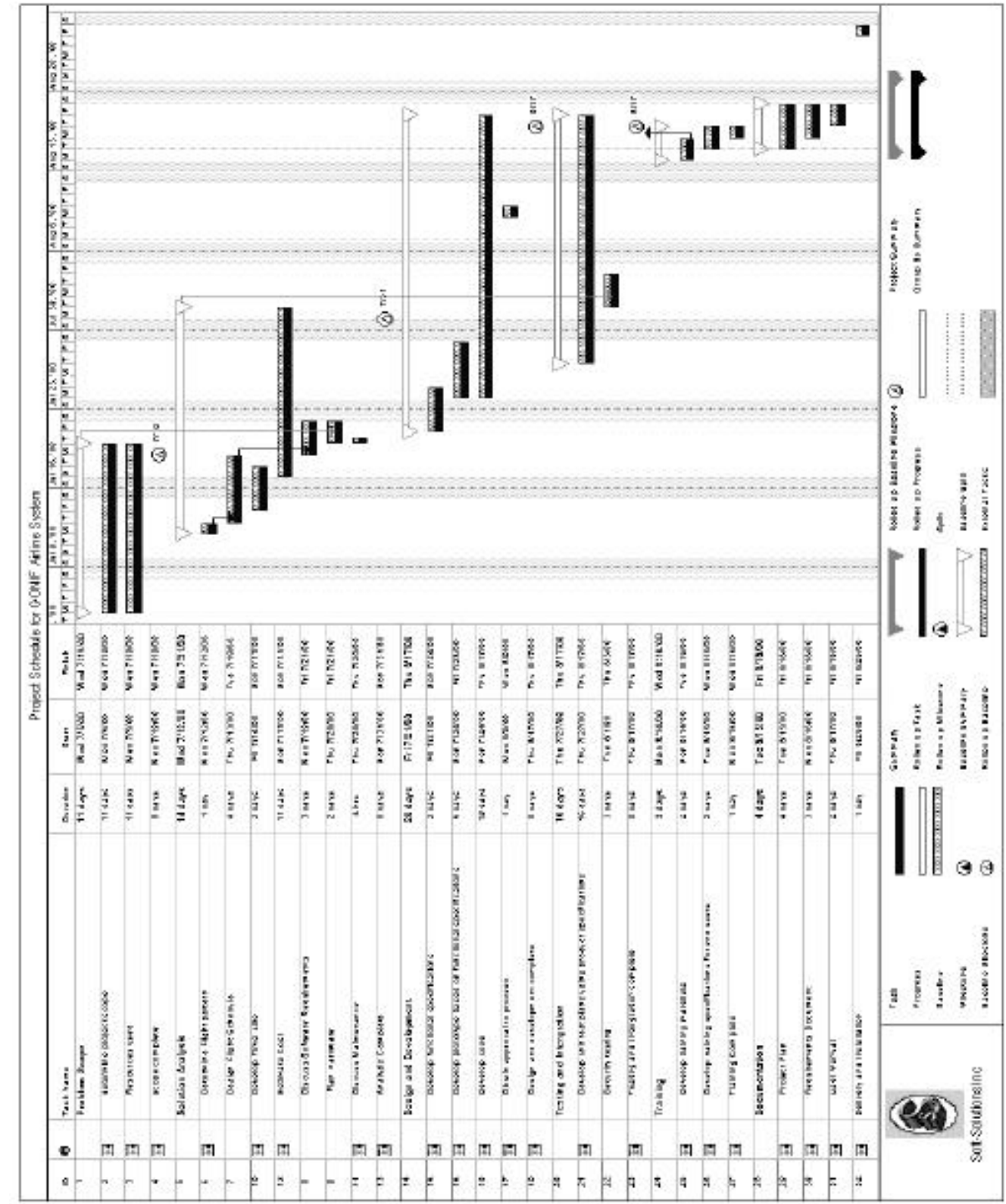

Proceedings of the 2001 American Society for Engineering Education Annual Conference \& Exposition Copyright (C) 2001, American Society for Engineering Education 


\section{Cost \& Maintenance Plan}

An overview of how much the whole system design will cost is outlined below:

$\mathbf{\$ 2 5 0 , 0 0 0}$ for the cost of system

* Includes hardware, software, implementation, and training.

$\$ \mathbf{1 0 , 0 0 0}$ starting price for any requested changes or upgrades in the system

$\$ \mathbf{\$ 0 . 0 0}$ for the yearly maintenance

*Excludes hardware failure due to additional improvement to the architecture of the machinery

The cost of the system's hardware with all specifications is as follows:

\section{Personal Computers for the users Price: \$1,299.00 each}

\section{Dell Dimension ${ }^{\circledR} 4100$ Series}

CPU: $\quad$ Pentium ${ }^{\circledR} 111$ Processor at $733 \mathrm{MHz}$

Memory: $\quad$ 128MB 133MHz SDRAM128M

Keyboard: $\quad$ Microsoft ${ }^{\circ}$ Internet Keyboard

Monitor: $\quad$ 17" (16.0" viewable,.28dp)E770E770

Video Card: 16MB ATI Rage 128 Pro16ATI

Hard Drive: 10GB Hard Drive (7200 RPM)

Floppy Drive: 3.5" Floppy Drive

OS: $\quad$ Microsoft $\quad$ Windows $\quad 98$

Mouse: $\quad$ Logitech MouseMan® Wheel

Network Card:3Com® ${ }^{\circledR}$ 3C905C TXM 10/100

Modem: Conexant V.90/56K Telephony

DVD-ROM Drive: $12 \mathrm{X}$ with Decoding

Sound Card: $\quad$ Soundblaster 64V PCI Sound Card

Speakers: Altec Lansing ACS-340 Speakers

Bundled Software: Microsoft@ Works Suite 2000 with Money 2000

Norton Antivirus ${ }^{\circledR}: \quad$ Norton Antivirus ${ }^{\circledR}$

Service: $\quad 1$ Year Next Business Day On-Site Parts and Labor, Years 2 and 3 Parts

\section{Emergency battery backup and surge system protector $\quad$ Price: \$129.99 each}

\section{Back-UPS APC 500}

The effects of power problems include keyboard lockup, complete data loss, hardware degradation, damaged motherboards, and more, making downtime inevitable.

An APC Back-UPS instantly switches your computer to emergency battery backup power and allows you to work through brief power outages or to shut down your system in the event of an extended outage.

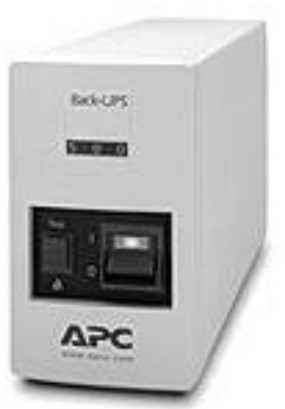




\section{Main Printer shared by the system's users}

\section{HP LaserJet 4050 Printer}

The industry leading office network printer with best in class combination of reliability, print quality, performance, and paper handling.

One of the chief characteristics of laser printers is their resolution (high dots per inch resolution). The available resolutions range from 300 to 1200 .

\section{Microsoft $®$ Windows and Access Licensing}

\section{Windows98}

Microsoft@ Windows 98 operating system can make your computer work and play better than ever before. It works better by making it simple to access the Internet, and by providing better system performance along with less maintenance. Your computer will increase in performance and reliability with faster application open and close times. Windows 98 also takes advantage of the newly emerging hardware technologies such as USB, DVD, multiple monitors, and WebTV.

With the purchase of windows there is a single user license included with the package. For four licenses, buying the four copies separately will be in the client's best interest, as it will cost less.

\section{Access2000}

Microsoft ${ }^{\circledR}$ Access 2000 makes it easy to get the information you need and provides powerful tools that help you organize and share your database so you and your team makes better decisions. In addition, find answers that count quickly, share information, and build faster and more effective business solutions. The licensing issue would be the same with the Access 2000 application as it is for Windows98.

\section{$\underline{\text { Human Interfaces }}$}

\section{Function keys}

The function keys for this program are the command keys mentioned above on the main switchboard screen, the little toolbars located on the bottom left side of the other screens.

\section{Keyboard Layout}

The letter keys and the numeric pad of the keyboard are used to enter the passenger's information into the system.

\section{Use of Mouse}

The mouse is also used as a mean for interface between the user and the system for selecting commands, moving screens, and assisting the operation with the keyboard. 


\section{$\underline{\text { Report Formats }}$}

\section{Users' Monitor Screens}

All the screenshots shown at the beginning of this document are taken from the program's output that will appear on each user's computer screen.

\section{Paper Reports from the Shared Printer}

In addition to the results on the users' screens, the mentioned forms and reports will have the same layout and look on the printed hard copies as the screen results.

\section{Printing the required screen}

When the user wants to print a specific screen, he/she can do the following:

-Press $\mathrm{Ctrl}+\mathrm{P}$ on the keyboard when the desired screen is highlighted with the mouse

-A window will come up on the screen in front of the program to select the setups, the number of copies, and the page numbers requested to print if there is more than one

-Pressing on the OK with the mouse will execute the print task and the box will disappear until the user makes another printing request.

\section{Input \& Output Data}

\section{Data Source}

The data comes form the passenger's phone calls to the reservation employees (users), who put that data into the program by using the keyboard and the mouse.

After the data manipulation by the computer and the program, the data and the results get saved on a disk and come on the screen by the users' choice.

\section{Data format}

The program runs Microsoft ${ }^{\circledR}$ Access2000, which deals with tables and fields in order to create relationships and structures between different pieces of input and output data as seen below.

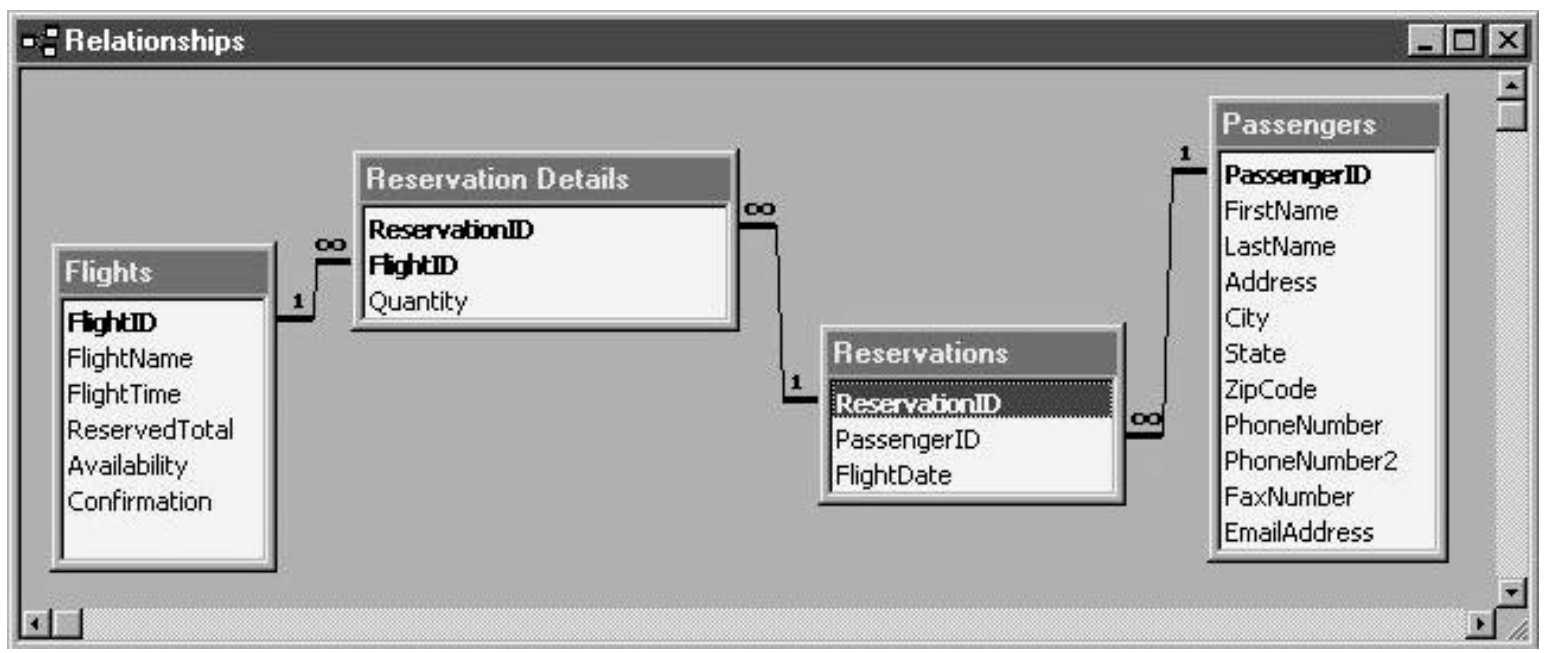


There are many-to-many relationships involved between the passengers and the flights, because the same flight holds more than one passenger and one passenger can have more than one flight in one day. The Reservation Details is the linking table that creates this kind of relationship in the program's database.

\section{Storage Media}

The data is backed up and stored automatically on the main computer that has the database file every time the program is exited or saved by one of the users.

\section{$\underline{\text { Performance Constraints }}$}

The available demo version of the program will be shown on the presentation day. It will include the screens and the lists discussed in this document, the data input and output forms for the next day flights, as well as most of the general functional characteristics of the program.

The program demo will be presented on our laptop, and it will not be possible for us to give paper copies of the results because we will not have it connected to a printer.

For these reasons, we will not be able to show how the system works for several days and in a network environment between the users.

\section{Fault-Handling Approach}

\section{Main Switchboard's Command Buttons}

The screen that has the command buttons doesn't need to handle errors because it only deals with user selection and switching.

\section{Fixed Flight List}

This is a static report that doesn't change and it is independent of the input program data, which doesn't need a fault-handler.

\section{Flight Schedule Report}

The flight schedule is a dynamic report that depends on the passenger data, but it is also locked from the users so that they can only view it or print it without modification (read-only).

\section{Enter/View Passenger Reservations}

Most of the data types on the Reservations screen has some sort of validation check, such as:

-The user cannot tamper or modify the Passenger ID for any reasons

-The Postal code must always be 5 digits, nothing else

-The phone and fax numbers must be kept in (398) 393-8384 format by the program

-The program must warn the user if he/she tries to change the Flight IDs to a value that does not exist in the program's database and force to change it back

-Reservation IDs must be locked and not allowed to be changes by the users 


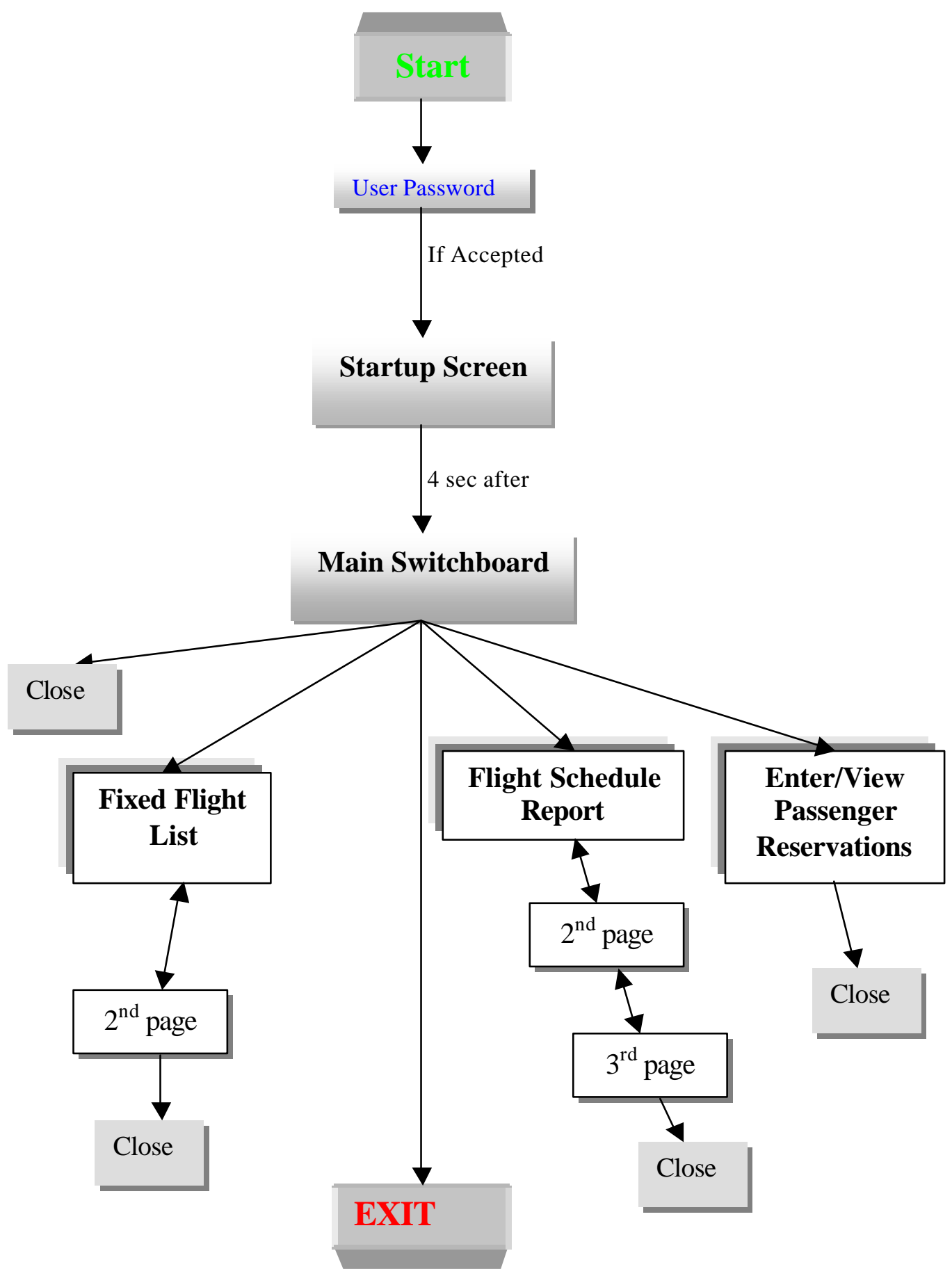

THE END 